\title{
Medication adherence issues in patients: focus on cost
}

This article was published in the following Dove Press journal:

Clinical Audit

8 March 2013

Number of times this article has been viewed

\section{Doreen Matsui}

Department of Pediatrics and Medicine, University of Western Ontario, London, Ontario, Canada; Children's Hospital, London Health Sciences Centre, London, Ontario, Canada; Children's Health Research Institute, London, Ontario, Canada

Correspondence: Doreen Matsui Children's Hospital, London Health Sciences Centre, 800 Commissioners Road East, London, Ontario, N6C 2V5 Canada,

$\mathrm{Tel}+\mathrm{I} 5196858268$

Fax + I 5196848156

Email dmatsui@uwo.ca

\begin{abstract}
Advances in drug therapy have resulted in efficacious treatments being available; however, the benefit may be lost if prescribed medications are not taken properly. Unfortunately, poor medication adherence is common and widespread, affecting all age groups and disease conditions. Adherence is a factor in health outcomes of pharmacotherapy with possible failure to achieve therapeutic goals and worsening of illness. Higher health care costs may result from more frequent physician and emergency department visits and increased hospitalization rates. The cost of medications may play a role in whether patients do or do not take their medication with increased cost sharing leading to poorer adherence with prescription drugs. Given the possible adverse consequences of nonadherence, interventions to improve medication-taking behavior are encouraged although not consistently successful. Surprisingly, there is relatively little information on the cost-effectiveness of these interventions and more methodologically sound research is needed in this area. Alternative strategies that have been proposed are valuebased insurance design and the use of financial incentives, although the former has not been widely accepted, and the latter is ethically controversial. This article reviews some of the main issues with regards to adherence with drug therapy including some of the cost implications of less than optimal medication adherence.
\end{abstract}

Keywords: adherence, medication, cost

\section{Introduction}

Efficacious drug therapy is available for many medical conditions; however, in order for patients to benefit they must take their medication as "drugs don't work in patients who don't take them". 'Indeed, it has been said that effective ways to help people follow medical treatments could have far larger effects on health than any treatment itself. $^{2}$ Nonadherence with drug therapy is not a new phenomenon as Hippocrates said, "keep watch also on the fault of patients, which often make them lie about the taking of things prescribed".

The World Health Organization defines adherence as the extent to which a person's behavior - taking medication, following a diet, and/or executing lifestyle changes corresponds with agreed recommendations from a health care provider. ${ }^{4}$ Although often used interchangeably with the term 'compliance', adherence is preferred by many as it acknowledges the patient's role in the decision-making process. ${ }^{5}$ Nonadherence may refer to not following the prescribed medication regimen, for example delayed or missing doses, with errors often the result of forgetfulness. Early, complete discontinuation of treatment is also common with persistence defined as the length of time between initiation and the last dose, which immediately precedes discontinuation. ${ }^{6}$ 
Clarity of the definition of both adherence and persistence is imperative when including these parameters in the economic evaluation of drug therapy.

Poor adherence to long-term therapies may compromise the effectiveness of treatment making this a critical issue both from the perspective of quality of life and of health economics. ${ }^{4}$ This article will provide a brief overview of medication adherence in general followed by a discussion of some of the cost implications of nonadherence with respect to effects on health outcomes and financial considerations. Detailed discussion of economic evaluations and modeling will not be included.

\section{Overview of adherence Scope of the problem}

Poor adherence with medical therapy may take many forms, including failing to fill the prescription, ${ }^{7}$ not taking prescribed medication or not taking it properly with respect to dose or timing, or prematurely discontinuing the treatment course. With the advent of electronic monitoring, various patterns of nonadherence have been described, including drug holidays (a period of 3 or more drug-free days) ${ }^{8}$ and "white coat compliance" (improvement in adherence prior to a scheduled medical appointment). ${ }^{9}$ Although ideally the dividing line between adherence and nonadherence with respect to percentage of doses taken would be based on the minimum coverage required to achieve the desired therapeutic benefit, this threshold is often not known and an arbitrary cut-off of $80 \%$ is often chosen. ${ }^{10}$

Nonadherence with drug therapy is widespread. In a metaanalysis of 569 studies from the 50-year period between 1948 and 1998, reported adherence to medical treatment ranged from $4.6 \%$ to $100 \%$ with a median of $76 \%$ and an overall average of $75.2 \% .{ }^{11}$ Subsequent research has confirmed that nonadherence remains a substantial problem. The seriousness of the underlying condition does not guarantee good medication-taking behavior as studies have shown less than optimal adherence even in patients with cancer ${ }^{12-14}$ or organ transplants. ${ }^{15,16}$ Adherence rates tend to be lower in patients with chronic medical disease compared to those with acute medical problems. As well, persistence among patients with chronic conditions is low and drops dramatically after the first 6 months of therapy. ${ }^{17}$

Not taking one's medication may result in treatment failure and unfavorable disease outcome. In 63 studies assessing patient adherence and outcomes of medical treatment, the outcome difference between high and low adherence was $26 \%$. ${ }^{18}$ The potential negative consequences of medication nonadherence will be discussed in detail in the section on cost implications.

\section{Factors affecting adherence}

Many factors have been proposed to play a role in poor adherence with drug treatment; however, no single factor has been shown to reliably predict which patients will or will not take their prescribed medication. Medication-taking behavior is influenced by a complicated interplay of factors that may include age, education level, socioeconomic status, patient beliefs, the provider-patient relationship, disease characteristics, and the drug regimen.

The more complex a drug regimen is, the more likely that it will not be followed. It has been stated that "treatments that are easier to take invite better adherence". ${ }^{19}$ Adherence is better when fewer medications are prescribed and when the administration schedule least disrupts the patient's normal busy routine. More frequent dosing may adversely affect adherence and once-daily dosing is often suggested as a preferred option. In a review of 76 studies where adherence was measured by electronic measuring devices, adherence declined as the number of daily doses increased with rates of $79 \%$ for one dose, $69 \%$ for two doses, $65 \%$ for three doses, and $51 \%$ for four doses. ${ }^{20}$ Subsequent work has also supported the benefit of less frequent dosing on medication adherence in chronic disease. ${ }^{21,22}$ Out-of-pocket costs of prescription drugs may also deter patients from taking their medications.

\section{Measurement of adherence}

In clinical practice, it is important to have a high index of suspicion that prescribed medication may not be taken, in particular in situations where the desired therapeutic goal is not achieved. Accurate assessment of adherence is also important in conducting pharmacoeconomic studies. The ideal measuring tool should be reliable, objective and provide a continuous record of medication-taking behavior. Unfortunately, no method is foolproof and no universally accepted gold standard exists. It has been stated that "simple methods are not accurate and accurate methods are not simple". ${ }^{23}$ Self-reporting using diaries, questionnaires, or interviews is commonly used as it is generally easy and inexpensive to implement; however, it may depend on recall and accuracy is often questioned as adherence is overestimated. Prescription refill is now more frequently utilized given the many computerized prescription databases that exist, but is limited by the assumption that medication that is prescribed or dispensed is actually taken. Pill counts, often used in the 
research setting, do not confirm ingestion, do not detect fluctuations in medication-taking behavior, and are subject to intentional pill dumping, and this leads to an overestimation of adherence. Measurement of drug levels, usually in blood, only reflects recent medication consumption, depends on the availability of an appropriate drug assay, and may be affected by pharmacokinetic variation between individuals.

With advances in technology, electronic monitoring of adherence with drug therapy has become more popular. Built-in microprocessors record and store information on the date and time of medication removal as a presumptive dose. ${ }^{24}$ Electronic monitors provide continuous real-time measurement and can provide information on temporal dosing patterns and allow correlation with breakthrough clinical events. Some monitors are equipped with the ability to remind the patient to take their drug at the correct time and others may be paired with telemedicine or the Internet to provide timely feedback to the patient regarding their medication-taking behavior. However, these systems, which are subject to mechanical malfunction, may be expensive and may not be suitable for routine clinical practice. ${ }^{25}$ As well, they generally record use of the device and do not confirm ingestion of the medication.

\section{Adherence-enhancing interventions}

Various adherence-enhancing interventions have been implemented to prevent poor adherence with drug therapy from occurring or to address it if it is recognized. Potential barriers to adherence need to be identified and efforts should target those patients who need the most support. Educational and behavioral approaches should be combined as no single intervention strategy has been shown to be effective across all patients, conditions, and settings. ${ }^{26}$ It has been stated that "while education alone cannot ensure compliance, ignorance certainly favors noncompliance". ${ }^{27}$

Individualization and tailoring of the drug regimen to accommodate the patient's lifestyle may be of value. With respect to the medications themselves, development of "forgiving" drugs, ie, drugs that are better able to maintain therapeutic action during the more common lapses in dosing, ${ }^{28}$ has been proposed as an attractive option. Fixed-dose combination preparations are also becoming more popular as they reduce pill burden and have been shown to decrease the risk of nonadherence. ${ }^{29}$ An interesting possibility is the polypill, which combines various drugs including blood pressurelowering drugs, a statin, and aspirin. ${ }^{30,31}$ More recently, the role of technology-based interventions, such as text messaging and telemonitoring systems, is being evaluated. ${ }^{32}$
In a Cochrane review of randomized controlled trials of interventions to help patients follow prescriptions for medications for medical problems, less than half of the interventions tested were associated with statistically significant improvements in medication adherence and only 29 of 93 interventions reported statistically significant improvements in treatment outcomes. ${ }^{2}$ A more recent review of randomized controlled trials assessing adherence-enhancing interventions found that of 62 trials, 33 (53\%) reported improvement in medication adherence with improvements in at least one health outcome in 18 (29\%). Effectiveness of the interventions varied across clinical conditions. Most consistent improvements in adherence and other health outcomes were noted with educational interventions with behavioral support through continued patient contact. ${ }^{33}$ A systematic review of interventions aimed at improving adherence to long-term medication in children suggested that adding a behavioral component to education may lead to better adherence, although there were also a number of negative studies. ${ }^{34}$ The International Expert Forum on Patient Adherence assigned the highest priority to the development of simple interventions that can be easily implemented in everyday practice. ${ }^{35}$

\section{Cost implications Consequences of nonadherence}

Poor adherence with drug therapy has cost implications, both in terms of health outcomes and financial burden. The clinical and economic impact of failure to be fully adherent will depend on the nature of the disease (acute or chronic, symptomatic or asymptomatic, nonfatal or potentially fatal) and the effectiveness of the therapy. ${ }^{36}$

\section{Health outcomes}

The relationship between inadequate adherence and unfavorable disease outcome has been demonstrated for many medical conditions. Good adherence with drug therapy was associated with lower mortality compared with poor adherence (odds ratio [OR] 0.56, 95\% confidence interval [CI]: $0.50-0.63) .{ }^{37}$ Other consequences of nonadherence may be inappropriate changes in treatment regimens or alterations in drug dosing leading to subsequent toxicity. Patients may undergo unnecessary investigations. Nonadherence may either be positively or negatively related to quality of life. ${ }^{38}$

There are many of examples of suboptimal adherence compromising the efficacy of drug regimens and leading to adverse outcomes. Patients who had a myocardial infarction 
who discontinued use of all their postdischarge medication (aspirin, $\beta$-blockers, and statins) at 1 month had a lower 1-year survival compared with patients who continued to take one or more medication(s). ${ }^{39}$ With coronary artery disease, nonadherence with prescribed medication was associated with increased all-cause mortality risk and higher cardiovascular mortality risk. ${ }^{40}$ Lower risk of all-cause death, stroke, or acute myocardial infarction was demonstrated in patients with good and excellent adherence to antihypertensive medications compared with those with poor adherence. ${ }^{41}$ Better adherence with statins was associated with reductions in all-cause mortality and fatal and nonfatal cardiovascular results. ${ }^{42}$ Adherence to diabetic pharmacotherapy was associated with better glycemic control ${ }^{43}$ while medication nonadherence was associated with an increased risk for all-cause mortality in patients with diabetes mellitus. ${ }^{44}$ Adherence with inhaled corticosteroids (greater than $75 \%$ of the prescribed dose) was associated with a reduction in asthma exacerbations. ${ }^{45}$ Disease flares in ulcerative colitis patients may be attributable to nonadherence with 5-aminosalicylic acid products. ${ }^{46}$ In pediatric renal transplant recipients, $14.4 \%$ of graft losses and $23.2 \%$ of late acute rejection episodes were associated with nonadherence to immunosuppressive drugs or potential interventions. ${ }^{47}$ There was a progressive increase in risk of relapse of acute lymphoblastic leukemia in children with decreasing levels of adherence to oral mercaptopurine. ${ }^{48}$ Association between poor adherence to antiretroviral therapy for HIV and virologic failure has been shown for protease inhibitors ${ }^{49}$ and nonnucleoside reverse transcriptase inhibitors. ${ }^{50}$ Nonadherence with antipsychotic medication was associated with an increased risk of relapse in patients with schizophrenia. ${ }^{51,52}$

Poor adherence with drug therapy has been implicated in increased hospitalization rates. Problems with patient adherence to medication were shown to be responsible for $33.3 \%$ (range $20.9 \%$ to $41.7 \%$ ) of preventable drug-related admissions to hospital. ${ }^{53}$ In the Hospital Admissions Related to Medication (HARM) study in the Netherlands, nonadherence to the medication regimen was a risk for potentially preventable medication-related hospital admissions (OR 2.3, 95\% CI: $1.4-3.8) .{ }^{54}$ Nonadherence was implicated in $50 \%$ of hospital admissions associated with drug-related problems to a pediatric hospital. ${ }^{55}$ Patients with cardiovascular disease who reported cost-related medication underuse were significantly more likely to be hospitalized in the next 2 years. ${ }^{56}$ Dietary and/or medication nonadherence was the reason for admission in $10.3 \%$ of heart failure hospitalizations. ${ }^{57}$ Disruptions in atypical antipsychotic adherence, with a gap of as short as 10 days past a missed prescription refill, were associated with increased mental health (hazard ratio 1.54, 95\% CI: 1.02-2.32) and schizophrenia-specific (hazard ratio 1.77, 95\% CI: 1.16-2.71) hospitalizations. ${ }^{58}$ Increased rates of hospitalization with low medication adherence have also been shown for several other medical conditions including hypertension, ${ }^{59}$ chronic obstructive pulmonary disease, ${ }^{60}$ diabetes mellitus, ${ }^{43,44,61}$ and Crohn's disease. ${ }^{62,63}$

\section{Financial burden (health care costs)}

Whether poor adherence with drug therapy results in increased overall financial costs depends on the balance between effects on drug spending and effects on expenditures resulting from altered health outcomes. Improvements in medication adherence may result in increased drug acquisition and pharmacy costs. ${ }^{64}$ It is often assumed that nonadherent patients will have a higher rate of health care resource utilization as poorer health outcomes may lead to increased ambulatory and emergency visits as well as hospital admissions. Increased risk of hospitalization may translate into significant excess costs. ${ }^{65}$ Patients not taking their medications may lead to lost productivity from work absenteeism and additional cost burden to family. At lower persistence rates, savings in drug costs may be outweighed by increases in nondrug costs. ${ }^{66}$ In assessing the effects of nonadherence on health care costs, it is important to bear in mind that inconsistency of definitions, difficulties with quantitative measurement, and other methodological issues may influence pharmacoeconomic analyses. ${ }^{38,67,68}$ Economic evaluations estimating cost-effectiveness need to take into account that adherence exhibited in randomized controlled trials is often better than that observed in real-life daily practice settings. ${ }^{69}$

Studies have shown that improved adherence is often associated with lower total health care costs, mainly as a result of reductions in hospitalizations and emergency department visits, ${ }^{64,70}$ although there are exceptions where there is an increase in overall costs, perhaps due to more expensive medications. ${ }^{64}$ The New England Healthcare Institute estimated that nonadherence along with suboptimal prescribing, drug administration, and diagnosis could result in as much as $\$ 290$ billion per year in avoidable medical spending in the United States. ${ }^{65}$

The economic consequences of nonadherence in cardiovascular disease and related conditions were addressed in a review of work published until 2007. Twenty-three studies, mostly retrospective using administrative claims databases in managed care organizations, examining the effect of 
adherence and/or persistence on the cost or cost-effectiveness of treatment were included. Higher levels of adherence were associated with lower nondrug costs, which offset the higher drug costs resulting in savings in overall health care costs and increased adherence rates appeared to reduce costeffectiveness ratios, although most studies failed to investigate the extent of the effect. ${ }^{71}$ A subsequently published study that examined medication adherence in patients with four chronic vascular conditions (congestive heart failure, hypertension, diabetes, and dyslipidemia) found that adherent patients had higher pharmacy spending than patients who were not adherent. However, improved adherence was associated with lower total annual health care spending as inpatient hospital days and emergency department visits were reduced. ${ }^{64}$

However, not all studies have shown a beneficial effect of better medication adherence, perhaps related to increased drug costs, particularly with more expensive products. For example, with respect to diabetes mellitus, one of the better studied medical conditions, although some studies have shown overall cost savings ${ }^{61,72}$ recent reviews of treatment adherence found that there was no consistent association between improved adherence and decreased health care costs. ${ }^{43,73}$

In the case of Crohn's disease, patients who were not adherent with infliximab maintenance therapy had higher medical, hospitalization, and outpatient costs. However, overall health care costs, taking into account that adherent patients incurred a greater outpatient infliximab cost, were not reported. ${ }^{62}$ Similarly, Carter et al reported higher hospital costs in nonadherent Crohn's disease patients not including the cost of infliximab administered in the outpatient setting, and therefore, it is difficult to assess the impact of infliximab nonadherence on total health care resource utilization and costs. ${ }^{63}$

Adherence with osteoporosis therapy is generally suboptimal. ${ }^{74} \mathrm{~A}$ recent paper that emphasized the importance of integrating medication adherence and persistence into pharmacoeconomic evaluations noted that a limited number of studies have suggested important economic implications of poor adherence to osteoporosis medications. ${ }^{69}$ Using a microsimulation model, Hiligsmann et al demonstrated that total costs were lower in a full adherence (with oral bisphosphonates) scenario than in the real-world adherence scenario as the averted costs of treating additional osteoporotic fractures resulting from nonadherence exceeded the cost of the additional therapy resulting from improved adherence. Oral bisphosphonates became more cost-effective with improved adherence. ${ }^{75}$
Using a model with assumptions regarding age, varying types of drug therapy, and number of drugs with a primary nonadherence (prescription not being filled) rate of 3\% and secondary nonadherence rates of $30 \%$ for short-term drug therapies and $50 \%$ for continuing ones, Hovstadius estimated the drug acquisition cost related to non-adherence to drug therapy in Sweden to be $42.6 \%$ of total drug acquisition costs. Ideally, the difference between primary and secondary nonadherence should be small to avoid wasteful spending. ${ }^{76}$

\section{Cost as a contributing factor to nonadherence}

Out-of-pocket costs may serve as a deterrent to patients obtaining their prescribed medication. Patients may skip doses, may split tablets to make them last longer, or may delay refilling prescriptions. ${ }^{77}$ An online survey of community participants found that out-of-pocket drug cost has a significant influence on one's preference to continue with a medication. ${ }^{78}$ Physicians often do not ask patients about how they pay for medications. ${ }^{79}$ Previous research, mostly from the United States, has shown that cost-related nonadherence to treatment is widespread, ${ }^{80}$ although as previously noted the etiology of nonadherence is often multifactorial and economic burden alone does not predict patient susceptibility to poor adherence. ${ }^{77}$ Patient-reported rates of cost-related underuse of prescription medications ranged from $1.6 \%$ to $22 \%$ in survey studies ${ }^{81}$ A review of cost-related nonadherence found that not having prescription drug coverage was a significant risk factor although the protection afforded varied by the source, duration, design features, and patient cost sharing. ${ }^{77}$ In a Canadian study, $9.6 \%$ of patients reported cost-related nonadherence. Lack of insurance for prescription drugs was associated with a more than fourfold increase in the odds of cost-related nonadherence. ${ }^{80}$ Behavior may vary depending on country of residence as for example, patients in the United States have been found to be two to three times more likely to report cost-related adherence than Canadian residents..$^{33}$ Identification of factors contributing to cost-related nonadherence may facilitate the development of strategies to reduce cost barriers.

The impact of medication costs on adherence is evident in work that has examined the role of cost sharing, that is shifting cost to patients or copayments. Increased cost sharing is associated with lower pharmaceutical use and, for some chronic conditions, increased use of medical services such as hospitalizations and emergency department visits. ${ }^{82}$ Eaddy et al conducted a literature review assessing the effects of increased cost sharing on adherence and outcomes 
in patients with neurological, cardiovascular, mental health, metabolic and pulmonary disorders. Fifty-six of 66 studies $(85 \%)$ demonstrated a significant relationship between increased patient cost sharing and decreased medication adherence. Furthermore, for each dollar increase in patient copayments, adherence would be expected to decrease by $0.4 \%$. Nineteen of 25 studies $(76 \%)$ demonstrated that increased patient cost sharing adversely affected outcomes. ${ }^{83}$ Increased cost sharing has been shown to delay the initiation of medications to treat newly diagnosed chronic disease. ${ }^{84}$ The impact of copayments on adherence may vary between patients with high- or low-comorbidity burden. ${ }^{85}$

\section{Cost-effectiveness}

\section{of adherence-enhancing interventions}

Given the many potential negative consequences of nonadherence, it would be advantageous to have effective strategies to improve medication-taking behavior. However, as previously noted the factors leading to poor adherence are many and strategies available to increase adherence are not always successful. Even the most effective interventions do not generally lead to large improvements in adherence and treatment outcomes. ${ }^{86}$ The cost of these adherence-enhancing interventions, which may be complex, labor intensive and inconvenient, need to be weighed against the benefits achieved, such as the prevention of adverse health outcomes, in order to determine their effects on overall health care costs. Ideally, the intervention will lead to better taking of drugs at a lower cost. Resources available must also be considered as the cost of implementation of some adherence-promoting strategies may be prohibitive in some low-resource settings, for example with treatment for tuberculosis in developing countries. ${ }^{87}$ However, the cost of implementing and sustaining these programs is often unknown ${ }^{88}$ and cost savings have not been explored in most studies. In a review of the costeffectiveness evidence, Elliot et al found that cost data was generally poorer than clinical data and that it was not possible to make definitive conclusions about the cost-effectiveness of medication adherence-enhancing interventions due to the heterogeneity of studies. ${ }^{89}$ Assessment studies often have shortcomings in their economic methodology and may be inadequate to assess cost-effectiveness accurately. ${ }^{90}$ As the trial period of studies of the cost-effectiveness of adherenceenhancing interventions is often short, it is not possible to determine long-term benefits. ${ }^{38}$

Assessment of the cost-effectiveness of adherenceenhancing interventions has been based largely on data from economic models. Studies have examined the effects of these interventions on adherence but have generally not looked directly at whether these strategies ultimately improve clinical outcomes. Using hypothetical scenarios and simulation, incremental cost-effectiveness ratios (ICERs) have been calculated..$^{91}$ This approach is subject to the limitations inherent in the uncertainty of the assumptions which are made in developing the model.

As an example, cost-effectiveness analyses of interventions to improve adherence with medications for cardiovascular indications have been undertaken. Using a Markov model simulating a cohort of postmyocardial infarction patients prescribed secondary prevention medications, only mailed education had an ICER of less than $\$ 100,000$ per quality-adjusted life year in an incremental analysis. ${ }^{92}$ A study to examine the cost-effectiveness of statin therapy for primary prevention of ischemic heart disease estimated that from $€ 243,000$ to $€ 413,000$ would be additionally spent on average every 10,000 person-year to avoid one ischemic heart disease event due to the enhancement of medication adherence. However, this model did not include the cost of the implementation strategies for enhancing adherence and did not account for several health benefits that may result from enhancing adherence. ${ }^{93}$ A review of adherence-improving interventions for antihypertensive and lipid-lowering drugs found that the most effective approaches were intensive and multifaceted and likely to be expensive. ${ }^{94}$ As a follow-up, this group compared the cost-effectiveness of various interventions and, based on their modeling, assessed that a combination program involving self-monitoring, reminders, and educational materials and a pharmacist/nurse management program were theoretically the most cost-effective methods of improving adherence with antihypertensive and lipid-lowering therapy. ${ }^{95}$

Although adherence may be improved by a program aimed at enhancing adherence, economic benefit does not necessarily follow. Despite improvement in treatment adherence in patients with schizophrenia or schizoaffective disorder, treatment adherence therapy, an intervention in which strategies for improving adherence are tailored to a patient's individual situation, did not result in improvement in psychiatric symptoms or quality of life and did not reduce total health care cost or contribute to cost-minimization compared to treatment as usual. ${ }^{96}$

\section{Value-based insurance design}

Reducing copayments for highly effective chronic therapies may improve adherence although this approach may not be sufficient on its own. ${ }^{86}$ Policy changes that reduced patients' 
out-of-pocket expenses for prescription medications through reduced medication copayments or improved prescription drug coverage had beneficial effects on adherence to cardiovascular and diabetes medications. ${ }^{33}$

The basis of value-based insurance design (VBID) is that cost sharing is set according to a medication's clinical value instead of its acquisition cost. ${ }^{97} \mathrm{VBID}$ plans lower employee out-of-pocket costs for cost-effective medications for chronic disease $^{65}$ and copayments for drugs of lower value are increased, ${ }^{98}$ although the latter has not always been applied. ${ }^{99}$ By removing financial barriers for high-value medications, the hope is that access to these drugs will improve, costrelated nonadherence will decrease, average health will be better, and health care costs will be reduced. VBID programs may be structured in a variety of ways. ${ }^{100}$ The most commonly implemented VBID programs lower copayments on classes of medications identified as high value. ${ }^{101}$ Ideally, ascertaining which therapies are of high value is evidence-based, determined by comparative effectiveness studies. ${ }^{101}$

The Mercer National Survey of Employer-Sponsored Health Plans indicated that many large employers were interested in implementing VBID plans. ${ }^{100}$ Assessments of the effects of VBID programs have mostly focused on the programs offered by self-insured employers. ${ }^{102}$ However, systems with a single payer providing comprehensive coverage over a longer period of time, such as Medicare, may have more incentive to adopt VBID plans than private insurers and employers. ${ }^{100}$

In a study of medications used to treat diabetes, hypertension, hyperlipidemia, and congestive heart failure, the implementation of a VBID program was associated with improved adherence ranging from $0.9 \%$ to $3.2 \%$ at 1 year and $2.2 \%$ to $5.0 \%$ at 2 years post-VBID adoption. Participants with the lowest baseline medication adherence underwent the largest increases in adherence following VBID adoption. ${ }^{97}$ Lowering statin copayments for patients with diabetes or vascular disease and clopidogrel copayments for all patients by a large self-insured employer was associated with increased prescriptions filling rates, reduced rates of physician visits, hospitalizations and emergency department admissions, and reduced patient out-of-pocket spending. However, rates of major coronary events or coronary revascularization procedures were not significantly changed and the policy was cost neutral with regard to overall health spending (combined insurer and patient spending for drugs and medical services). ${ }^{103}$

Although studies have shown positive effects of VBID programs on adherence, ${ }^{102,104,105}$ it is not clear whether VBID can result in net cost savings ${ }^{98,106}$ and adoption of VBID has been slow. ${ }^{106}$ It is unclear whether increased use of high-value therapies leads to better health outcomes and reductions in other health care costs. ${ }^{100}$ It has been argued that the modest improvements in adherence may not be clinically meaningful and economic evaluations have suggested that VBID is cost neutral. ${ }^{97}$ If copayments are reduced, health care plans are unable to realize enough subsidization of the increase in use of high-value medications from reduction in use of low-value medications. ${ }^{99}$ It has also been suggested that there are not enough avoidable costs to fully offset the copayment reductions and that many of the copayment waivers go to people who are already adherent to their prescribed regimen. ${ }^{99}$

\section{Use of other financial incentives}

Another option which has been proposed to encourage medication adherence is to provide direct financial incentives. Patients who display better adherence may receive financial rewards ${ }^{86}$ Discounts and rebates for drugs may be linked to improved adherence among patients. ${ }^{65}$ Reduced health insurance premiums or copayments may be offered to patients who adhere closely to their medications. ${ }^{65}$

A meta-analysis demonstrated that financial reinforcement interventions significantly improved adherence with an overall effect size of 0.77 (95\% CI: 0.70-0.84). Interventions that were longer in duration, provided an average reinforcement of $\$ 50$ or more per week, and reinforced patients at least weekly showed the most potential. ${ }^{107}$ A systematic review of incentive-based medication adherence interventions found adherence increased by a mean of $20 \%$, but that adherencepromoting effects tended to lessen after the intervention was discontinued. ${ }^{108}$ Economic feasibility and cost-effectiveness of this promising approach remains to be determined. Ethical considerations will also need to be further debated. ${ }^{109,110}$

In summary, suboptimal adherence with drug therapy is a significant issue with cost implications including compromised health outcomes and economic consequences related to increased health care spending. In addition, out-of-pocket medication costs may contribute to poor medicationtaking behavior. Reducing medication nonadherence (and nonpersistence) may have the potential to reduce the financial burden to society by decreasing medical costs and overall health care expenditure, although how to best accomplish this task remains to be determined. The existing literature suggests that potential cost savings of interventions to improve adherence with drug therapy have generally not been addressed in detail. In addition to better identifying what elements work most effectively with different patient groups ${ }^{88}$ 
high quality cost-effectiveness analysis of the different strategies to enhance medication adherence are needed to balance the trade-off between resources required to implement the intervention (including increased medication costs) versus the degree of improvement in adherence, incremental health benefits, decreased use of health care services, and associated cost savings, if any. Ideally, these studies should also take into account whether these interventions lead to improvement in health outcomes and quality of life at a reasonable price.

\section{Disclosure}

The author has no conflicts of interests to report.

\section{References}

1. Bonaccorso S. Perspectives from the pharmaceutical industry. $B M J$. 2003;327(7419):863-864.

2. Haynes RB, Ackloo E, Sahota N, McDonald HP, Yao X. Interventions for enhancing medication adherence. Cochrane Database Syst Rev. 2008;2:CD000011.

3. Tebbi CK. Treatment compliance in childhood and adolescence. Cancer. 1993;71(Suppl 10):S344-S3449.

4. World Health Organization. Adherence to long-term therapies Evidence for action [online]. Available from: http://www.who.int/ chp/knowledge/publications/adherence_full_report.pdf. Accessed November 7, 2012.

5. Tilson HH. Adherence or compliance: changes in terminology. Ann Pharmacother. 2004;38(1):161-162.

6. Vrijens B, De Geest B, Hughes DA, et al. A new taxonomy for describing and defining adherence to medications. $\mathrm{Br} J$ Clin Pharmacol. 2012;73(5):691-705.

7. Fischer MA, Stedman MR, Lii J, et al. Primary medication nonadherence: analysis of 195,930 electronic prescriptions. J Gen Intern Med. 2010;25(4):284-290.

8. Pullar T. Compliance with drug therapy. Br J Clin Pharmacol. 1991; 32(5):535-539.

9. Feinstein AR. On white-coat effects and the electronic monitoring of compliance. Arch Int Med. 1990;150(7):1377-1378.

10. Cramer JA, Roy A, Burrell A, et al. Medication compliance and persistence: terminology and definitions. Value Health. 2008;11(1):44-47.

11. DiMatteo MR. Variations in patients' adherence to medical recommendations - A quantitative review of 50 years of research. Med Care. 2004;42(3):200-209.

12. Foulon V, Schöffski P, Wolter P. Patient adherence to oral anticancer drugs: an emerging issue in modern oncology. Acta Clinica Belgica. 2011;66(2):85-96.

13. Kondryn HJ, Edmondson CL, Hill J, Eden TO. Treatment nonadherence in teenage and young adult patients with cancer. Lancet Oncol. 2011;12(1):100-108.

14. Butow P, Palmer S, Pai A, Goodenough B, Luckett T, King M. Review of adherence-related issues in adolescents and young adults with cancer. J Clin Oncol. 2010;28(32):4800-4809.

15. Germani G, Lazzaro S, Gnoato F, et al. Nonadherent behaviors after solid organ transplantation. Transplant Proc. 2011;43(1):318-323.

16. Dew MA, DiMartini AF, De Vito Dabbs A, et al. Rates and risk factors for nonadherence to the medical regimen after adult solid organ transplantation. Transplantation. 2007;83(7):858-873.

17. Osterberg L, Blaschke T. Adherence to medication. $N$ Engl J Med. 2005;353(5):487-497.

18. DiMatteo MR, Giordani PJ, Lepper HS, Croghan TW. Patient adherence and medical treatment outcomes - A meta-analysis. Med Care. 2002;40(9):794-811.
19. Bender BG. Overcoming barriers to nonadherence in asthma treatment. J Allergy Clin Immunol. 2002;109(Suppl 6):S554-S559.

20. Claxton AJ, Cramer J, Pierce C. A systematic review of the associations between dose regimens and medication compliance. Clin Ther. 2001;23(8):1296-1310.

21. Coleman CI, Limone B, Sobieraj DM, et al. Dosing frequency and medication adherence in chronic disease. J Manag Care Pharm. 2012;18(7): 527-539.

22. Saini SD, Schoenfeld P, Kaulback K, Dubinsky MC. Effect of medication dosing frequency on adherence in chronic diseases. Am J Manag Care. 2009;15(6):e22-e33.

23. McNicholas F. To adhere or not, and what we can do to help. Eur Child Adolesc Psychiatry. 2012;21(12):657-663.

24. Cramer JA. Microelectronic systems for monitoring and enhancing patient compliance with medication regimens. Drugs. 1995;49(3):321-327.

25. Ingerski LM, Hente EA, Modi AC, Hommel KA. Electronic measurement of medication adherence in pediatric chronic illness: a review of measures. J Pediatr. 2011;159(4):528-534.

26. Mahtani KR, Heneghan CJ, Glasziou PP, Perara R. Reminder packaging for improving adherence to self-administered long-term medications. Cochrane Database Syst Rev. 2011;9:CD005025.

27. Nevin TE. "Why do they do that?" The compliance conundrum. Pediatr Nephrol. 2005;20(7):845-848.

28. Urquhart J. Patient non-compliance with drug regimens: measurement, clinical correlates, economic impact. Eur Heart J. 1996;17(Suppl A): $8-15$.

29. Bangalore S, Kamalakkannan G, Parkar S, Messerli FH. Fixed-dose combinations improve medication compliance: a meta-analysis. $\mathrm{Am} \mathrm{J}$ Med. 2007;120(8):713-719.

30. Wald NJ, Law MR. A strategy to reduce cardiovascular disease by more than $80 \%$. BMJ. 2003;326(7404):1419.

31. Wald NJ, Wald DS. The polypill concept. Heart. 2010;96(1):1-4.

32. Granger BB, Bosworth HB. Medication adherence: emerging use of technology. Curr Opin Cardiol 2011;26(4):279-287.

33. Viswanathan $\mathrm{M}$, Golin $\mathrm{CE}$, Jones $\mathrm{CD}$, et al. Interventions to improve adherence to self-administered medications for chronic diseases in the United States: a systematic review. Ann Intern Med. 2012;157(11):785-795.

34. Dean AJ, Walters J, Hall A. A systematic review of interventions to enhance medication adherence in children and adolescents with chronic illness. Arch Dis Child. 2010;95(9):717-723.

35. van Dulmen S, Sluijs E, van Dijk L, de Ridder D, Heerdink R, Bensing J. Furthering patient adherence: a position paper of the international expert forum on patient adherence based on an internet forum discussion. $B M C$ Health Serv Res. 2008;8:47.

36. Hughes DA, Bagust A, Haycox A, Walley T. Accounting for noncompliance in pharmacoeconomic evaluations. Pharmacoeconomics. 2001; 19(12):1185-1197.

37. Simpson SH, Eurich DT, Majumdar SR, et al. A meta-analysis of the association between adherence to drug therapy and mortality. $B M J$. 2006;333(7557): 15 .

38. Cleemput I, Kesteloot K, DeGeest S. A review of the literature on the economics of noncompliance. Room for methodological improvement. Health Policy. 2002;59(1):65-94.

39. Ho PM, Spertus JA, Masoudi FA, et al. Impact of medication therapy discontinuation on mortality after myocardial infarction. Arch Intern Med. 2006;166(17):1842-1847.

40. Ho PM, Magid DJ, Shetterly SM, et al. Medication nonadherence is associated with a broad range of adverse outcomes in patients with coronary artery disease. Am Heart J. 2008;155(4):772-779.

41. Esposti LD, Saragoni S, Benemei S, et al. Adherence to antihypertensive medications and health outcomes among newly treated hypertensive patients. Clinicoecon Outcomes Res. 2011;3:47-54.

42. Simpson RJ Jr, Mendys P. The effects of adherence and persistence on clinical outcomes in patients treated with statins: a systematic review. J Clin Lipidol. 2010;4(6):462-471. 
43. Asche C, LaFleur J, Conner C. A review of diabetes treatment adherence and the association with clinical and economic outcomes. Clin Ther. 2011;33(1):74-109.

44. Ho PM, Rumsfeld JS, Masoudi FA, et al. Effect of medication nonadherence on hospitalization and mortality among patients with diabetes mellitus. Arch Intern Med. 2006;166(17):1836-1841.

45. Williams LK, Peterson EL, Wells K, et al. Quantifying the proportion of severe asthma exacerbations attributable to inhaled corticosteroid nonadherence. J Allergy Clin Immunol. 2011;128(6):1185-1191.

46. Higgins PD, Rubin DT, Kaulback K, Schoenfield PS, Kane SV. Systematic review: impact of non-adherence to 5-aminosalicylic acid products on the frequency and cost of ulcerative colitis flares. Aliment Pharmcol Ther. 2009;29(3):247-257.

47. Dobbels F, Ruppar T, De Geest S, Decorte A, Van Damme-Lombaerts R, Fine RN. Adherence to the immunosuppressive regimen in pediatric kidney transplant recipients: a systematic review. Pediatr Transplant. 2010;14(5):603-613.

48. Bhatia S, Landier W, Shangguan M, et al. Nonadherence to oral mercaptopurine and risk of relapse in Hispanic and non-Hispanic white children with acute lymphoblastic leukemia: a report from the children's oncology group. J Clin Oncol. 2012;30(17):2094-2101.

49. Paterson DL, Swindells S, Mohr J, et al. Adherence to protease inhibitor therapy and outcomes in patients with HIV infection. Ann Intern Med. 2000;133(1):21-30.

50. Nachega JB, Hislop M, Dowdy DW, Chaisson RE, Regensberg L, Maartens G. Adherence to nonnucleoside reverse transcriptase inhibitor-based HIV therapy and virologic outcomes. Ann Intern Med. 2007;146(8):564-573.

51. Morken G, Widen JH, Grawe RW. Non-adherence to antipsychotic medication, relapse and rehospitalization in recent-onset schizophrenia. BMC Psychiatry. 2008;8:32.

52. Novick D, Haro JM, Suarez D, Perez V, Dittmann RW, Haddad PM. Predictors and clinical consequences of non-adherence with antipsychotic medication in the outpatient treatment of schizophrenia. Psychiatry Res 2010;176(2-3):109-113.

53. Howard RL, Avery AJ, Slavenburg S, et al. Which drugs cause preventable admissions to hospital? A systematic review. Br J Clin Pharmacol. 2007;63(2):136-147.

54. Leendertse AJ, Egberts AC, Stoker LK, van den Bemt PM. Frequency of and risk factors for preventable medication-related hospital admissions in The Netherlands. Arch Intern Med. 2008;168(17):1890-1896.

55. Easton KL, Parsons BJ, Starr M, Brien JE. The incidence of drug-related problems as a cause of hospital admissions in children. Med J Aust. 1998;169(7):356-359.

56. Heisler M, Choi H, Rosen AB, et al. Hospitalizations and deaths among adults with cardiovascular disease who underuse medications because of cost: a longitudinal analysis. Med Care. 2010;48(2):87-94.

57. Ambardekar AV, Fonarow GC, Hernandez AF, Pan W, Yancy CW, Kranz MJ. Characteristics and in-hospital outcomes for nonadherent patients with heart failure: finding from Get With The Guidelines-Heart Failure (GWTC-HF). Am Heart J. 2009;158(4):644-652.

58. Law MR, Soumerai SB, Ross-Degnan D, Adams AS. A longitudinal study of medication nonadherence and hospitalization risk in schizophrenia. J Clin Psychiatry. 2008;69(1):47-53.

59. Dragomir A, Côté R, Roy L, et al. Impact of adherence to antihypertensive agents on clinical outcomes and hospitalization costs. Med Care. 2010;48(5):418-425.

60. Vestbo J, Anderson JA, Calverley PM, et al. Adherence to inhaled therapy, mortality and hospital admission in COPD. Thorax. 2009;64(11): 939-943.

61. Encinosa WE, Bernard D, Dor A. Does prescription drug adherence reduce hospitalizations and costs? The case of diabetes. Adv Health Econ Health Serv Res. 2010;22:151-173.

62. Kane SV, Chao J, Mulani PM. Adherence to infliximab maintenance therapy and health care utilization and costs by Crohn's disease patients. Adv Ther. 2009;26(10):936-946.
63. Carter CT, Waters HC, Smith DB. Effect of a continuous measure of adherence with infliximab maintenance treatment on inpatient outcomes in Crohn's disease. Patient Prefer Adherence. 2012;6:417-426.

64. Roebuck MC, Liberman JN, Gemmill-Toyama M, Brennan TA. Medication adherence leads to lower health care use and costs despite increased drug spending. Health Aff (Millwood). 2011;30(1): 91-99.

65. New England Healthcare Institute. Thinking outside the pillbox A system-wide approach to improving patient medication adherence for chronic disease. Aug 2009. Available from: http://www.nehi. net/publications/44/thinking_outside_the_pillbox_a_systemwide_ approach_to_improving_patient_medication_adherence_for_chronic_ disease. Accessed November 8, 2012.

66. Hughes D. When drugs don't work - Economic assessment of enhancing compliance with interventions supported by electronic monitoring devices. Pharmacoeconomics. 2007;25(8):621-635.

67. Hughes D, Cowell W, Koncz T, Cramer J. Methods for integrating medication compliance and persistence in pharmacoeconomic evaluations. Value Health. 2007;10(6):498-509.

68. Hughes DA, Bagust A, Haycox A, Walley T. The impact of noncompliance on the cost-effectiveness of pharmaceuticals: a review of the literature. Health Econ. 2001;10(7):601-615.

69. Hiligsmann M, Boonen A, Rabenda V, Reginster J. The importance of integrating medication adherence into pharmacoeconomic analyses: the example of osteoporosis. Expert Rev Pharmacoecon Outcomes Res. 2012;12(2):159-166.

70. Sokol MC, McGuigan KA, Verbrugge RR, Epstein RS. Impact of medication adherence on hospitalization risk and healthcare cost. Med Care. 2005;43(6):521-530.

71. Muszbek N, Brixner D, Benedict A, Keskinaslan A, Khan ZM. The economic consequences of noncompliance in cardiovascular disease and related conditions: a literature review. Int J Clin Pract. 2008;62(2): 338-351.

72. Egede LE, Gebregziabher M, Dismuke CE, et al. Medication nonadherence in diabetes: longitudinal effects on costs and potential cost savings from improvement. Diabetes Care. 2012;35(12):2533-2539.

73. Breitscheidel L, Stamenitis S, Dippel FW, Schöffski O. Economic impact of compliance to treatment with antidiabetes medication in type 2 diabetes mellitus: a review paper. J Med Econ. 2010;13(1):8-15.

74. Adachi JD, Josse RG, Russell RG. If you don't take - it can't work: the consequences of not being treated or nonadherence to osteoporosis therapy. Ther Clin Risk Manag. 2011;7:181-198.

75. Hiligsmann M, Rabenda V, Bruyère $O$, Reginster J. The clinical and economic burden of non-adherence with oral bisphosphonates in osteoporotic patients. Health Policy. 2010;96(2):170-177.

76. Hovstadius B, Petersson G. Non-adherence to drug therapy and drug acquisition costs in a national population - a patient-based register study. BMC Health Serv Res. 2011;11:326.

77. Briesacher BA, Gurwitz JH, Soumerai SB. Patients at-risk for costrelated medication nonadherence: a review of the literature. J Gen Intern Med. 2007;22(6):864-871.

78. Laba TL, Brien JA, Jan S. Understanding rational non-adherence to medications. A discrete choice experiment in a community sample in Australia. BMC Fam Pract. 2012;13(1):61.

79. Zheng B, Poulose A, Fulford M, Holbrook A. A pilot study on cost-related medication nonadherence in Ontario. J Popul Ther Clin Pharmacol. 2012;19(2):e239-e247.

80. Law MR, Cheng L, Dhalla IA, Heard D, Morgan SG. The effect of cost on adherence to prescription medications in Canada. CMAJ. 2012;184(30):297-302.

81. Kirking DM, Lee JA, Ellis JJ, Briesacher B, McKercher PL. Patient-reported underuse of prescription medications: a comparison of nine surveys. Med Care Res Rev. 2006;63(4):427-446.

82. Goldman DP, Joyce GF, Zheng Y. Prescription drug cost sharing Association with medication and medical utilization and spending and health. JAMA. 2007;298(1):61-69. 
83. Eaddy MT, Cook CL, O’Day K, Burch SP, Cantrell R. How patient cost-sharing trends affect adherence and outcomes - A literature review. P T. 2012;37(1):45-55.

84. Solomon MD, Goldman DP, Joyce GF, Escarce JJ. Cost sharing and the initiation of drug therapy for the chronically ill. Arch Intern Med. 2009;169(8):740-748

85. Wang V, Liu CF, Bryson CL, Sharp ND, Maciejewski ML. Does medication adherence following a copayment increase differ by disease burden? Health Serv Res. 2011;46(6 Pt 1):1963-1985.

86. Bosworth HB, Granger BB, Mendys P, et al. Medication adherence: a call for action. Am Heart J. 2011;162(3):412-424.

87. M'Imunya JM, Kredo T, Volmink J. Patient education and counseling for promoting adherence to treatment for tuberculosis. Cochrane Database Syst Rev. 2012;5:CD006591.

88. Van Servellen G, Heise BA, Ellis R. Factors associated with antidepressant medication adherence and adherence-enhancement programmes: a systematic literature review. Ment Health Fam Med. 2011;8(4): 255-271.

89. Elliot RA, Barber N, Home R. Cost-effectiveness of adherenceenhancing interventions: a quality assessment of the evidence. Ann Pharmacother. 2005;39(3):508-515.

90. Golay A. Pharmacoeconomic aspects of poor adherence: can better adherence reduce healthcare costs? J Med Econ. 2011;14(5): 594-608.

91. Patrick AR, Schousboe JT, Losina E, Solomon DH. The economics of improving medication adherence in osteoporosis: validation and application of a simulation model. J Clin Endocrinol Metab. 2011;96(9): $2762-2770$

92. Ito K, Shrank WH, Avorn J, et al. Comparative cost-effectiveness of interventions to improve medication adherence after myocardial infarction. Health Serv Res. 2012;47(6):2097-2117.

93. Corrao G, Scotti L, Zambon A, et al. Cost-effectiveness of enhancing adherence to therapy with statins in the setting of primary cardiovascular prevention. Evidence from an empirical approach based on administrative databases. Atherosclerosis. 2011;217(2):479-485.

94. Chapman RH, Ferrufino CP, Kowal SL, Classi P, Roberts CS. The cost and effectiveness of adherence-improving interventions for antihypertensive and lipid-lowering drugs. Int J Clin Pract. 2010;64(2): 169-181.

95. Chapman RH, Kowal SL, Cherry SB, Ferrufino CP, Roberts CS, Chen L. The modeled lifetime cost-effectiveness of published adherence-improving interventions for antihypertensive and lipidlowering medications. Value Health. 2010;13(6):685-694.
96. Gilden J, Staring ABP, van der Gaag M, Mulder CL. Does treatment adherence therapy reduce expense of healthcare use in patients with psychotic disorders? Cost-minimization analysis in a randomized controlled trial. Schizophr Res. 2011;133(1-3):47-53.

97. Farley JF, Wansink D, Lindquist JH, Parker JC, Maciejewski ML. Medication adherence changes following value-based insurance design. Am J Manag Care. 2012;18(5):265-274.

98. Encinosa WE. Value-based insurance design in Medicare. Appl Health Econ Health Policy. 2009;7(3):149-154.

99. Melnick SJ, Motheral BR. Is "value-based" value wasted? Examining value-based insurance designs through the lens of cost-effectiveness. J Manag Care Pharm. 2010;16(2):130-133.

100. Choudhry NK, Rosenthal MB, Milstein A. Assessing the evidence for value-based insurance design. Health Aff (Millwood). 2010;29(11): 1988-1994.

101. de Souza JA, Ratain MJ, Fendrick AM. Value-based insurance design: aligning incentives, benefits, and evidence in oncology. J Natl Compr Canc Netw. 2012;10(1):18-23.

102. Frank MD, Fendrick AM, He Y, et al. The effect of a large regional health plan's value-based insurance design program on statin use. Med Care. 2012;50(11):934-939.

103. Choudhry NK, Fischer MA, Avorn JL, et al. The impact of reducing cardiovascular medication copayments on health spending and resource utilization. J Am Coll Cardiol. 2012;60(18):1817-1824.

104. Fendrick AM, Martin JJ, Weiss AE. Value-based insurance design: more health at any price. Health Serv Res. 2012;47(1 Pt 2): 404-413

105. Zeng F, An JJ, Scully R, Barrington C, Patel BV, Nichol MB. The impact of a value-based benefit design on adherence to diabetes medications: a propensity score-weighted difference in difference evaluation. Value Health. 2010;13(6):846-852.

106. Fairman KA, Curtiss FR. What do we really know about VBID? Quality of the evidence and ethical considerations for health plan sponsors. J Manag Care Pharm. 2011;17(2):156-174.

107. Petry NM, Rash CJ, Byrne S, Ashraf S, White WB. Financial reinforcers for improving medication adherence: findings from a meta-analysis. Am J Med. 2012;125(9):888-896.

108. DeFulio A, Silverman K. The use of incentives to reinforce medication adherence. Prev Med. 2012;55 Suppl:S86-S94.

109. Burns T. Is it acceptable for people to be paid to adhere to medication? Yes. BMJ. 2007;335(7613):232.

110. Shaw J. Is it acceptable for people to be paid to adhere to medication? No. BMJ. 2007;335(7613):233.
Clinical Audit

\section{Publish your work in this journal}

Clinical Audit is an international, peer-reviewed, open access journa focusing on the processes and outcomes of clinical audit in any area of healthcare. All aspects of patient care are addressed within the journal and practitioners from all disciplines are invited to submit their work. Areas covered include: Publication of audits; How an audit has changed practice;

\section{Dovepress}

Practical tips on how to do audits and to avoid pitfalls; How audits have changed patient care; Calls and justifications for new audits. The manuscript management system is completely online and includes a very quick and fair peer-review system, which is all easy to use. Visit http://www.dovepress. com/testimonials.php to read real quotes from published authors. 